\title{
Parental health status and children's eating behaviors: An epidemiological study in 1728 Greek 10-12 years old students
}

\author{
Maria Bogri', Aikaterini Kanellopoulou', Venetia Notara², George Antonogeorgos', \\ Andrea-Paola Rojas-Gil ${ }^{3}$, Ekaterina Kornilaki ${ }^{4}$, Maria-Eleni Kordoni ${ }^{1}$, Anna Velentza', \\ Magdalini Mesimeri ${ }^{1}$, Rena I. Kosti ${ }^{5}$, Areti Lagiou' ${ }^{2}$, Demosthenes B. Panagiotakos ${ }^{1,6}$
}

'Department of Nutrition and Dietetics, School of Health Science and Education, Harokopio University, Athens, Greece 2Department of Public and Community Health, Laboratory of Hygiene and Epidemiology, School of Public Health, University of West Attica, Athens, Greece

${ }^{3}$ Department of Nursing, Faculty of Health Sciences, University of Peloponnese, Tripoli, Greece

${ }^{4}$ Department of Preschool Education, School of Education, University of Crete, Rethymnon, Greece

${ }^{5}$ Department of Nutrition and Dietetics, School of Physical Education, Sports and Dietetics, University of Thessaly,

Trikala, Greece

${ }^{6}$ Faculty of Health, University of Canberra, ACT, Australia

\begin{abstract}
Aim: Although the parental influence on children's dietary habits has been widely studied, little is known about the effect of parental health status on children's dietary behavior. Thus, the association between the parental burden of cardiometabolic disease and its impact on children's eating habits and behaviors was examined. Material and Methods: 1,728 children aged 10-12 years old along with one of their parents were enrolled in a cross-sectional study conducted during 2014-2016. Among others, children's dietary habits and parental medical history were recorded. Children's adherence to the Mediterranean diet (MD) was evaluated through the KIDMED score while the parental health status was assessed through a cardiometabolic risk score calculated for this study. The working sample was 1,133 children with a recorded parental health status.
\end{abstract}

\section{Corresponding author:}

Prof. Demosthenes B. Panagiotakos, Dr Med, FRSPH, FACE

Professor of Biostatistics - Epidemiology of Nutrition

School of Health Sciences \& Education

Department of Nutrition and Dietetics

Harokopio University, Athens, Greece

70 Eleftheriou Venizelou (Thiseos) Ave.

Kallithea, Athens, 17671 Greece

T.: +302109549332 / +302109549100

E-mail: dbpanag@hua.gr 
Results: Most parents (92.1\%) reported at most 2 cardiometabolic risk factors including overweight/obesity, diabetes mellitus, hypertension, and dyslipidemia. Ordinal logistic regression analyses showed a significant association between children's eating habits and adherence to the MD with the parental burden of cardiovascular disease. Children showed $6 \%$ higher odds of higher adherence to the MD (OR: 1.06, 95\% Cl: 1.01-1.12) and $54 \%$ lower odds of not having breakfast at all (OR: $0.46,95 \% \mathrm{Cl}: 0.27-0.80)$ for a one-unit increase in the cardiometabolic risk score. The stratified analysis revealed a significant association between KIDMED score and CVD risk score only among boys (OR: $1.09,95 \% \mathrm{Cl}: 1.01-1.18)$. Conclusions: Parental health status is positively associated with children's dietary behavior and adherence to the MD indicating an additional source of influence.

KEY WORDS: Childhood obesity, dietary habits, parental health, cardiovascular disease, medical history

\section{INTRODUCTION}

Cardiovascular diseases (CVDs) remain the predominant cause of death globally and a healthy dietary pattern is considered the cornerstone of cardiovascular disease prevention and treatment. ${ }^{1,2}$ The adoption of healthy dietary patterns such as the Mediterranean diet in childhood has been associated with lower adulthood cardiovascular disease risk. ${ }^{3,4}$ Moreover, taking into consideration that dietary health behaviors and food preferences are established in early childhood and follow into adulthood ${ }^{(5)}$ and that childhood obesity has reaching alarming levels worldwide ${ }^{6}$ the parental role in shaping the children's dietary habits is of enormous importance.

Indeed, family-based interventions have been recognized as an important approach to tackle childhood obesity and to stop obesity tracking into adulthood, provided that interventions should be implemented address to children younger than 12 years, before behavioral patterns are resistant to change. 7,8 Parental influences on children's dietary behavior decline due to the greater effect of genetic background as children grow older. ${ }^{9}$ Therefore, parents consist a key influence on shaping children's eating behavior either by their own dietary intake or by the food parenting practices that they follow intentionally. ${ }^{9}$ Modeling is considered a passive process of influence when occurs from the psychological affiliation and the behavioral mimicry which happens unconsciously whereas food parenting practices are regarded as more active processes. ${ }^{9,10}$ Children perceive parental dietary patterns and especially maternal food choices as reference for the shaping of their own dietary habits. ${ }^{11}$ Experimental studies have shown that children are more likely to consume an unfamiliar food if they see another person eating it. ${ }^{12}$ Food parenting practices are an additional source of parental influence on children's eating habits in an active way, classified into three main categories including coercive control, structure and autonomy support. ${ }^{13}$ Evidence suggests that food parenting practices that directly influence home food environment like, food availability and accessibility are more important and effective in stimulating healthy children's intake in contrast to those affecting children's appetite (restriction, pressure, rewarding). ${ }^{9}$

Despite the fact that the parental role has been broadly studied ${ }^{14-16}$ and is highly associated with children's dietary behavior, parental health status and its effect on children's dietary habits, has been scarcely examined. To the best of our knowledge only one cross sectional study has been found to investigate the influence of increased parental burden of disease on children's dietary intake, although without significant associations. ${ }^{17}$ Thus, the aim of the present study was to investigate the association between the parental burden of cardiometabolic risk factors and their impact on children's eating habits and behaviors among 10-12 years old children.

\section{METHODS}

\section{Design}

This was a cross-sectional, observational epidemiological study.

\section{Setting}

In the school years 2014-2015 and 2015-2016, data were collected from 47 primary schools from 5 different Greek towns. The towns that took part in the study included Athens the metropolis of Greece, Heraklion the capital city of Crete (the largest Greek island), and three counties of the Peloponnese peninsula (Sparta, Kalamata, and Pyrgos). The selected regions represent large urban and rural municipalities and therefore a more representative sample was obtained. The specific schools were randomly selected from the Greek Ministry of Education list of schools. The schools were located as follows: 37 in Athens, 5 in Heraklion, 3 in Pyrgos, 2 in Kalamata, and 5 in Sparta.

\section{Study sample}

In total 1728 students (795 boys) aged 10-12 years old were enrolled in the study. All children's parents were also 
invited to participate, with a $68.9 \%$ response rate being achieved ( $n=1190)$. The participation rate for students ranged from $95 \%$ to $100 \%$ between schools, without any significant differences between the studied areas. However, for the purposes of the present analysis, the examined sample was limited to 1133 students (488 boys), whose parents had reported their health status.

\section{Power analysis}

The working sample was adequate to evaluate effect size measures' differences of $20 \%$ at $<5 \%$ level of significance, achieving $85 \%$ statistical power.

\section{Measurements}

Specific questionnaires, designed for this study, were completed anonymously by each child after the researcher's or school teacher's request. For higher rates of accuracy in the responses, the study's investigators, in collaboration with children's teachers, assisted the process by using practical examples. The questionnaires included a variety of questions concerning socio-demographic characteristics (age, gender, place of residence, nationality), daily activities and habits (i.e., physical and sedentary activities, outdoor activities, dietary habits, and smoking), knowledge and perceptions on risk factors for chronic diseases. Anthropometric measurements (height, weight for BMI calculation) using scale and tape over skin-tight clothes with no shoes were also recorded. Children's dietary habits evaluation was conducted through a validated semi-quantitive Food Frequency Questionnaire (FFQ) designed for 10-12 years old children living in Greece. ${ }^{18}$ The FFQ provided information for dietary habits as well as habits pertaining to mealtime behaviors. All meals consumed in a day, as well as the type and size of snacks, were recorded. Specifically, the frequency of consumption of foods outside home (including school canteens and non-home-made meals), the cooking method usually employed by the family, the type of oils/fat consumed, the frequency of snacks consumed and the frequency of consumption of various foods such as fish, poultry, red meat, eggs, white bread, whole grain bread, potatoes, rice, fruits, vegetables, fruit juices, soda drinks, low-calorie soft drinks, beverages, and of traditionally cooked meals, were also recorded by children and their parents or guardians. For the purposes of the present analysis the behaviors examined were: the frequency of breakfast consumption consisting of 5 categories (never/ almost never, 1-2 times/week, 3-4 times/week, 5-6 times/ week, everyday), the frequency of soft drinks consumption consisting of 6 categories (never/ $<1 /$ month, $1-3$ times/ month, once/week, 2-6 times/week, 1 time/day, $>2$ times/ day) and the frequency of chocolates/croissants/biscuits consisting of 6 categories (never/ $<1 /$ month, $1-3$ times/ month, once/week, 2-6 times/week, 1 time/day, >2 times/ day). In the last two variables, the categories once/day and $>2$ times/day were combined due to the small number of children consuming soft drinks or chocolates/croissants/ biscuits more than 2 times a day.

Furthermore, parental questionnaires were completed by any of their parents at home and they were asked to return them back to the school setting. The majority of the questionnaires were completed by one parent and usually by the mother (75\%). The parental questionnaires included questions about anthropometric self-reported characteristics (height, weight), parental and child medical history, family socioeconomic status (maternal and paternal education, profession and annual income status), lifestyle characteristics (physical activity, smoking, etc.), and dietary habits (frequency of several food groups consumption).

\section{Children's adherence to Mediterranean diet}

The adherence to the Mediterranean diet (MD) was evaluated with the aid of the KIDMED index (MD quality index for children and adolescents). The index ranged from 0 to 12 and was based on a 16-question test. Dietary habits that were negatively correlated with MD were assigned with -1 , dietary habits that were positively correlated with MD were assigned with +1 , while dietary habits with neutral correlation were assigned with 0 . The sums of the values from the administered test were classified into three levels: 1) >8, i.e. optimal Mediterranean Diet; 2) 4-7, i.e. improvement needed to adjust intake to Mediterranean patterns; 3 ) $\leq 3$, i.e. very low diet quality. ${ }^{19}$

\section{Parental health status}

Parental health status was evaluated with the use of a cumulative risk score of established cardiometabolic risk factors, which was developed for the purposes of this study. ${ }^{20}$ Specifically, the score included four variables concerning the presence of cardiometabolic risk factors, i.e: a) overweight/obesity (Body Mass Index (BMI) $\geq 25 \mathrm{~kg} / \mathrm{m}^{2}$, according to the World Health Organization categorization $\mathrm{BMI}$ was calculated as weight in $\mathrm{Kg}$ divided by height in $\mathrm{m}$ squared), b) diabetes mellitus (fasting glucose $\geq 126 \mathrm{mg} /$ dl or use of anti-diabetic medication), c) hypertension (systolic/diastolic blood pressure $\geq 140 / 90 \mathrm{mmHg}$ or use of anti-hypertensive medication), d) dyslipidaemia (LDLcholesterol $>100 \mathrm{mg} / \mathrm{dL}$ or total cholesterol $>200 \mathrm{mg} / \mathrm{dl}$ or special medication). For the presence of each of the aforementioned conditions a score +1 was assigned to the individual. Thus, the total score (CVD risk score) ranged from 0 to 4 . A score equal to 4 indicated the highest cardiometabolic risk profile and referred to an obese adult 
with all the aforementioned comorbidities, whereas score equal to 0 indicated the absence of the aforementioned health conditions. The CVD risk score was implemented as ordinal rather than continuous scale, under the assumption that each added CVD risk factor has the same and additive effect in the overall parental CVD risk.

\section{Bioethics}

The study was approved by the Institute of Educational Policy of the Ministry of Education and Religious Affairs (code of approval F15/396/72005/C1) and was carried out in accordance with the Declaration of Helsinki (1989). Prior to their acceptance, the school principals, teachers, parents, and students were fully informed about the aims and procedures of the study. A signed parental consent was obtained before the completion of the questionnaires.

\section{Statistical analysis}

Continuous variables are presented as mean \pm standard deviation, while categorical variables are presented as absolute and relative (\%) frequencies. Association between normally distributed continuous variables and categorical with more than 3 categories was evaluated through the one-way ANOVA test. The Chi-squared test was used to evaluate the association between categorical variables. Additionally, ordinal logistic regression was used to assess the likelihood of affecting children's dietary behavior according to the parental burden of cardiovascular disease (measured by the CVD risk score). The proportionality of odds assumption was tested using the likelihood ratio test and it was met for all the analyses ( $p$-values $>0.05$ ). All models were adjusted for age and interactions terms were implemented, in order to investigate for the possible interaction effect of sex in the aforementioned associations. The results are presented as odds ratios (OR) along with their corresponding $95 \%$ confidence interval (95\% Cl). Collinearity among the variables was tested through the variance inflation factor (VIF). Two-sided hypothesis tests were considered setting the level of statistical significance at 5\%. All analyses were conducted using STATA 15.0 (M. Psarros \& Assoc., Sparti, Greece).

\section{RESULTS}

In total, 1133 parents ( 816 females), of the 1190 parents participated in the study, reported their health status. The majority of them (92.1\%) reported at most 2 cardiometabolic risk factors including overweight/obesity, diabetes mellitus, hypertension and dyslipidemia; 59.1\% reported no cardiometabolic risk factors. In Table 1 parental characteristics, their health status and children's eating habits and adherence to the Mediterranean diet are presented. In regards to children's eating habits, the average of KIDMED score was $4.66 \pm 2.29$ units. Specifically, $57.5 \%$ of children, needed improvement to adjust intake to Mediterranean diet patterns, $31.1 \%$ of children had very low-quality diet, while $11.5 \%$ of children had the optimal Mediterranean diet. In total, daily breakfast consumption was a common dietary behavior followed by the majority of children (62.7\%), while $56.4 \%$ of children reported that they drunk soft drinks at most 3 times/week. Regarding the consumption of chocolates/croissants/biscuits, $71.2 \%$ of children reported that they consumed such products at most once/ week. A significant positive correlation was reported between breakfast consumption and parental CVD risk score $(p<0,001)$; the more the CVD risk factors parents reported the more frequently children used to consume breakfast. A similar association between soft drinks consumption and CVD risk score of parents $(p=0.014)$ was also observed; the more the CVD risk factors parents reported the more frequently children used to consume soft drinks. No association was observed between chocolates/croissants/biscuits consumption and parental burden of cardiovascular disease.

Table 2 presents the results of ordinal logistic regression models to assess the association between children's eating habits and adherence to the Mediterranean diet and parental burden of cardiovascular disease. According to the analysis, for one more CVD risk factor, children had $6 \%$ higher odds to have higher adherence to the Mediterranean diet (OR: 1.06, 95\% Cl: 1.01-1.12) (Model 1). Additionally, for one more CVD risk factor, children had 54\% lower odds of not having breakfast at all (OR: $0.46,95 \% \mathrm{Cl}: 0.27-0.80)$ and $34 \%$ lower odds of having breakfast 1-2 times per week (OR: 0.66, 95\% Cl: 0.47-0.94) in relation to children having breakfast every day (Model 2). No association between soft drinks consumption and parental burden of disease was observed (Model 3) and between chocolates/croissants/biscuits consumption and parental CVD risk score (Model 4). Furthermore, a possible effect modification of children's sex was hypothesized in the relation between CVD risk score and the various eating habits and assessed with the corresponding interaction term in each of the four models. All $p$-values were significant $(p<0.005)$, thus stratified analysis according to sex was performed. The results are presented in Figure 1. The association between KIDMED score and CVD risk score was significant only among boys (OR: 1.09, 95\% Cl: 1.01-1.18).

\section{DISCUSSION}

The aim of this study was to investigate the association between the parental burden of cardiometabolic risk factors and the dietary behaviors and eating habits of their children. The results of our study revealed that almost six out of ten children required improvement to adjust dietary intakes to Mediterranean dietary patterns and children 
Parental health status and children's eating behaviors

TABLE 1. Children eating characteristics, as well as level of adherence to the Mediterranean diet, overall, and by burden of cardiometabolic risk factors among the parents.

\begin{tabular}{|c|c|c|c|c|c|c|c|}
\hline & \multirow[b]{2}{*}{ Overall } & \multicolumn{5}{|c|}{ Cardiometabolic Risk Score of parents } & \multirow[b]{2}{*}{$P$} \\
\hline & & 0 & 1 & 2 & 3 & 4 & \\
\hline \multicolumn{8}{|l|}{ Parental characteristics } \\
\hline Age (years), father, mean (sd) & $45.83(5.24)$ & $46.50(5.11)$ & $44.91(5.45)$ & $46.75(5.25)$ & $47.39(4.40)$ & $47.34(6.37)$ & $<0.001$ \\
\hline Age (years), mother, mean (sd) & $41.51(4.42)$ & $41.39(4.51)$ & $41.03(4.58)$ & $41.91(3.99)$ & $42.80(3.46)$ & $42.48(5.05)$ & 0.049 \\
\hline Sex, female, n (\%) & $816(74.7)$ & $434(53.2)$ & $181(22.2)$ & $135(16.5)$ & $41(5.0)$ & $25(3.1)$ & $<0.001$ \\
\hline \multicolumn{8}{|l|}{ Children Characteristics } \\
\hline KIDMED Score (-4 to 12$)$, mean (sd) & $4,66(2.29)$ & $4.51(2.28)$ & $4.90(2.27)$ & $4.78(2.26)$ & $5.09(2.41)$ & $4.94(2.20)$ & 0.104 \\
\hline Frequency of breakfast consumption, n (\%) & & & & & & & $<0.001$ \\
\hline Never or almost never & $71(6.3)$ & $52(73.2)$ & $10(14.1)$ & $9(12.7)$ & $0(0.0)$ & $0(0.0)$ & \\
\hline 1-2 times/week & $166(14.8)$ & $112(67.5)$ & $20(12.0)$ & $26(15.7)$ & $4(2.4)$ & $4(2.4)$ & \\
\hline 3-4 times/week & $109(9.7)$ & $60(55.0)$ & $23(21.1)$ & $20(18.3)$ & $6(5.5)$ & $0(0.0)$ & \\
\hline 5-6 times/week & $74(6.6)$ & $36(48.6)$ & $12(16.2)$ & $18(24.3)$ & $4(5.4)$ & $4(5.4)$ & \\
\hline Everyday & $705(62.7)$ & $403(57.2)$ & $116(16.5)$ & $119(16.9)$ & $40(5.7)$ & $27(3.8)$ & \\
\hline Frequency of soft drinks consumption, $\mathrm{n}(\%)$ & & & & & & & 0.014 \\
\hline Never or less than $1 /$ month & $445(39.3)$ & $258(58.0)$ & $88(19.8)$ & $72(16.2)$ & $21(4.7 \%)$ & $6(1.3)$ & \\
\hline $1-3$ times/month & $302(27.1)$ & $178(58.9)$ & $44(14.6)$ & $58(19.2)$ & $16(5.3)$ & $6(2.0)$ & \\
\hline once/week & $223(20.0)$ & $137(61.4)$ & $32(14.3)$ & $34(15.2)$ & $8(3.6)$ & $12(5.4)$ & \\
\hline 2-6 times/week & $72(6.5)$ & $39(54.2)$ & $9(12.5)$ & $17(23.6)$ & $3(4.2)$ & $4(5.6)$ & \\
\hline 1 time/day & $55(4.9)$ & $31(56.4)$ & $6(10.9)$ & $8(14.5)$ & $4(7.3)$ & $6(10.9)$ & \\
\hline$>2$ times/day & $18(1.6)$ & $10(55.6)$ & $2(11.1)$ & $3(16.7)$ & $2(11.1)$ & $1(5.6)$ & \\
\hline $\begin{array}{l}\text { Frequency of chocolates/croissant/ } \\
\text { biscuits consumption, } \mathrm{n}(\%)\end{array}$ & & & & & & & 0.190 \\
\hline Never $/<1 /$ month & 241 (21.9) & $148(61.4)$ & 45 (18.7) & $34(14.1)$ & $11(4.6)$ & $3(1.2)$ & \\
\hline $1-3$ times/month & $298(27.1)$ & $175(58.7)$ & $47(15.8)$ & $51(17.1)$ & $17(5.7)$ & $8(2.7)$ & \\
\hline once/week & $252(22.2)$ & $146(57.9)$ & $41(16.3)$ & $46(18.3)$ & $7(2.8)$ & $12(4.8)$ & \\
\hline 2-6 times/week & $174(15.8)$ & $100(57.5)$ & $26(14.9)$ & 34 (19.5) & $8(4.6)$ & $6(3.4)$ & \\
\hline 1 time/day & $106(9.4)$ & $60(56.6)$ & $15(14.2)$ & $17(16.0)$ & $9(8.5)$ & $5(4.7)$ & \\
\hline$>2$ times/day & $30(2.7)$ & $21(70.0)$ & $3(10.0)$ & $6(20.0)$ & $0(0.0)$ & $0(0.0)$ & \\
\hline
\end{tabular}

$\mathrm{sd}=$ standard deviation, KIDMED = Mediterranean Diet Quality Index for children and adolescents

with the parental burden of disease were more likely to adhere to the Mediterranean diet while the association remained statistically significant only for boys. Similar sex differences on adherence to the Mediterranean diet in children have also been reported in previous studies. ${ }^{21,22}$ Additionally, our findings showed that children with the parental burden of disease were more likely to consume breakfast daily while no significant association was observed for the rest eating behaviors.

It is worth mentioning, that in the present study the vast majority of parents reported at most two cardiometa- bolic risk factors, a finding which is justified by the results of ATTICA study which revealed that the incidence of CVD and the related risk factors are at high levels among the Greek population despite the various recent strategies of public health that have been implemented. ${ }^{23}$ The evaluation of children's eating characteristics in the present study showed that almost one out of ten children conformed to the Mediterranean diet pattern while more than half of them, required improvement to adjust their eating habits to the certain pattern. These findings are consistent with previous cross-sectional studies that examined children's 
TABLE 2. Results from ordinal logistic regression analyses (odds ratio, OR, $95 \%$ confidence interval, $\mathrm{Cl}$ ) that evaluated the association between children's adherence to the Mediterranean diet and other selected eating behaviors, in relation to parental burden of cardiometabolic risk factors. All models were adjusted for age of children.

\begin{tabular}{lcccc}
\hline & Model 1 & Model 2 & Model 3 & Model 3 \\
\hline Age (per 1 year) & $0.88(0.77,1.01)$ & $0.90(0.73,1.17)$ & $0.86(0.74,0.99)^{*}$ & $0.86(0.75,0.99)^{*}$ \\
Sex (boys vs. girls) & $0.94(0.74,1.18)$ & $0.58(0.42,0.78)^{*}$ & $0.92(0.73,1.17)$ & $0.92(0.73,1.17)$ \\
KIDMED score & $1.06(1.01,1.12)^{*}$ & & &
\end{tabular}

Frequency of breakfast consumption

$\begin{array}{lc}\text { Never or almost never } & 0.46(0.27,0.80)^{*} \\ 1-2 \text { times/week } & 0.66(0.47,0.94)^{*} \\ \text { 3-4 times/week } & 0.99(0.67,1.46) \\ \text { 5-6 times/week } & 1.41(0.90,2.20)\end{array}$

Everyday

Ref

Frequency of soft drinks consumption

$\begin{array}{lc}\text { Never or less than } 1 / \text { month } & 0.65(0.26,1.58) \\ \text { 1-3 times/month } & 0.69(0.28,1.69) \\ \text { once/week } & 0.65(0.26,1.62) \\ 2-6 \text { times/week } & 0.93(0.35,2.45) \\ 1 \text { time/day } & 0.95(0.35,2.60) \\ >2 \text { times/day } & \text { Ref }\end{array}$

$>2$ times/day

$1.30(0.58,2.94)$

$1.58(0.71,3.53)$

$1.63(0.73,3.66)$

$1.69(0.74,3.85)$

$1.87(0.80,4.38)$

1 time/day

$>2$ times/day

Ref

* $\mathrm{p}<0.05, \mathrm{OR}=$ Odds Ratio, $\mathrm{Cl}=$ Confidence Interval, KIDMED = Mediterranean Diet Quality Index for children and adolescents

and adolescents' adherence to the Mediterranean diet through KIDMED score,in Greek population and showed that the majority of children were in the intermediate level of adherence suggesting a need for improvement. ${ }^{24,25}$ On the other hand, in the present study it seems that breakfast consumption was a common dietary behavior among the children. Indeed, in many countries has been reported that a high percentage of children are regular breakfast consumers. ${ }^{26}$ Literature suggests that breakfast consumption is associated with better educational and cognitive performance in children and adolescents while skipping breakfast in adulthood is associated with increased risk for cardiovascular and all-cause mortality. ${ }^{27,28}$

Our study also showed that children with parents with an increased burden of cardiometabolic risk factors had a higher likelihood of adherence to the Mediterranean diet.
This finding is not consistent with that found in another cross-sectional study including more than 11,000 parents and children, suggested that the adult CVD risk does not influence the dietary intake of children residing in the same household given the limited compliance of the affected parents to the recommended dietary guidelines. ${ }^{17}$ However, in the present study the conformity of parents to the recommended dietary guidelines for the prevention of CVD, could not be assessed given the lack of data relevant to their previous habits. However, in our study, the potential improvement of parental dietary behavior does not seem to be a plausible explanation behind the observed association since literature shows that patients experience difficulties in following the recommended guidelines relevant to lifestyle changes for the management of chronic diseases. In particular, current evidence found that patients' 


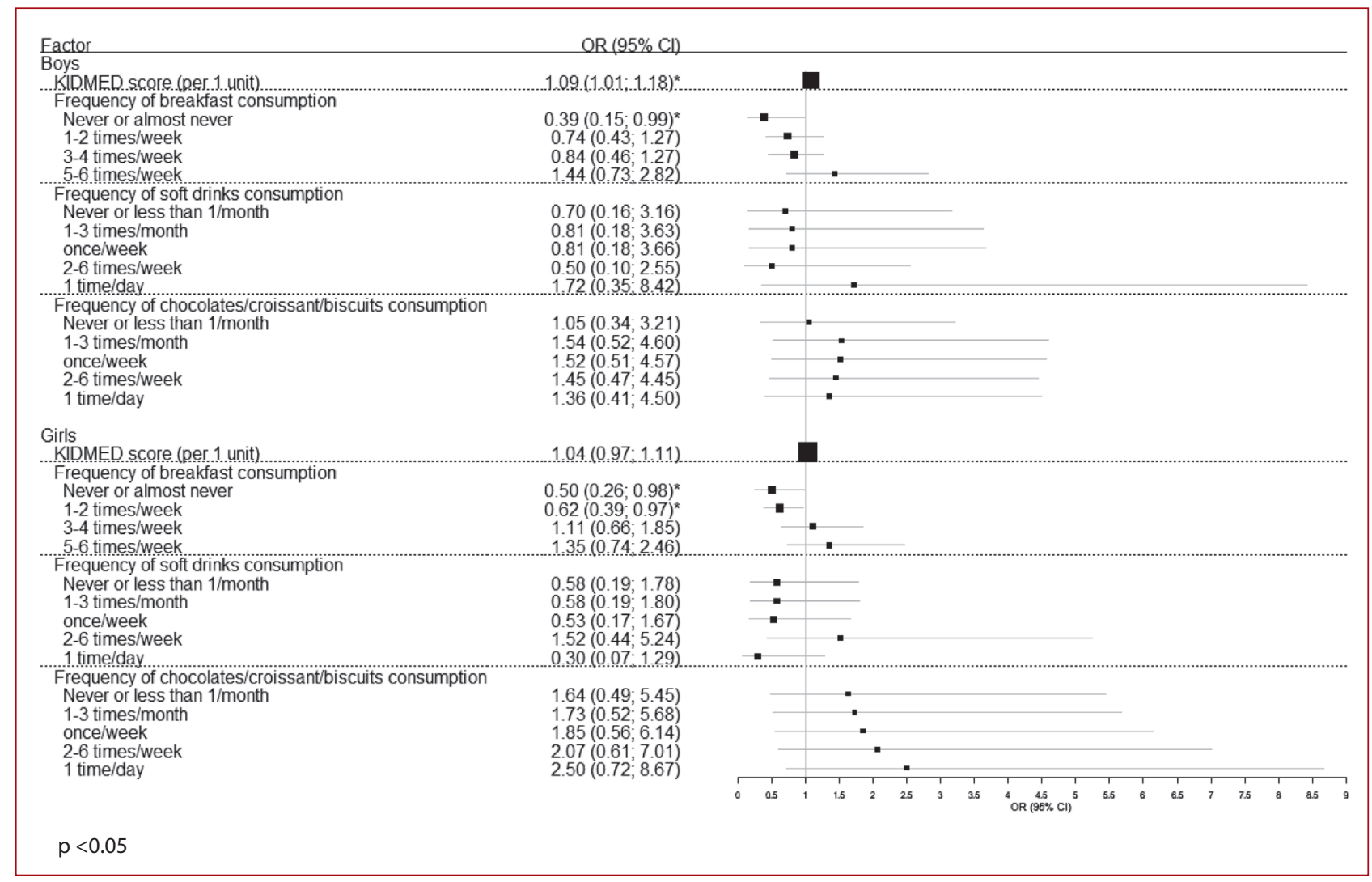

FIGURE 1. The ORs along with their $95 \% \mathrm{Cls}$ for the association of adherence to the Mediterranean Diet, dietary habits and parental health status stratified by children' sex and adjusted for age.

adherence to guidelines for the management of cardiovascular disease, metabolic syndrome, hypertension, and diabetes was reported to be quite poor. ${ }^{17,29-31}$ Thus, taking into consideration that parental dietary habits are not the only source of influence on children's eating behavior ${ }^{9}$ it seems that the observed association between the parental cardiometabolic disease burden and the improved diet quality of their children could be attributed to the applied food parenting practices. Indeed, according to the results of a recent meta-analysis of 37 observational studies regarding the impact of parental behavior and practices on children's eating behavior, parental modeling effects and availability showed the strongest association with both healthy and unhealthy food consumption. ${ }^{32}$ Specifically, several studies support that children are more likely to consume food that is available and easily accessible at home. ${ }^{33}$ In addition, another cross-sectional study including 386 parents of children aged 2 to 17 years old showed that food availability in the family environment can change regardless of parental dietary intake as long as parents understand the increased health risk of positive family history for their children. ${ }^{34}$

Additionally, our findings showed that children with affected parents were more likely to adhere to healthy eating habits such as breakfast consumption. This may be attributed to the fact that breakfast time is a sharing habit as the family's members eat together and hence family meals have a protective influence on children's dietary behavior. ${ }^{35-37}$ Thus, both parental modeling and food parenting practices could be considered as possible influencers. It is worth mentioning that in our study, no significant association was observed between children with affected parents and the rest eating behaviors as regards soft drinks and sweets which are easily accessible out of the home environment since these dietary behaviors can get away from parental control in contrast with breakfast consumption which takes place usually at home. ${ }^{38}$

The Mediterranean diet is highly associated with favorable effects on cardiometabolic health and potential protective role against overweight and obesity while its beneficial contribution in human's health is highlighted by the decision of UNESCO to include this dietary pattern on the representative List of Intangible Cultural Heritage of Humanity. ${ }^{39-42}$ In addition, adherence to the Mediterranean diet is suggested by international guidelines for the prevention and treatment of cardiovascular disease. ${ }^{43,44}$ Despite all the increasing data of the benefits of the Mediterranean diet a shift towards unhealthy eating habits and poor diet quality is documented, especially at young ages. ${ }^{45}$ 
Therefore parents need to understand their crucial role in influencing children's dietary behavior and should be empowered to model healthy behaviors for their children.

This was across-sectional study and has, therefore, several limitations that should be considered. No temporal relationship and hence causal inferences can be made. Furthermore, despite the initial attempt to achieve generalizability, the sample was originated from specific regions of Greece, which limits the generalizability of the findings to the entire Greek children's population aged 1012 years. However, due to the stratified random sampling scheme and the large sample size, its representativeness could be considered high for urban settings. Data related to diet were collected from FFQ (food frequency questionnaires) instead of food diaries or repeated 24-hour recalls. A potential limitation may also be reporting bias due to the self-reporting questionnaires. However, the presence of a trained investigator throughout the completion of the questionnaire for addressing any potential misconceptions about it increases the validity of the given responses. Parental weight and height were self-reported; thus, they may be subjected to bias due to overestimate height and underestimate weight. ${ }^{46}$ In addition, the majority of parents who completed the questionnaires were mothers and this may result in bias to less burden of CVD risk factors since women become more susceptible to CVD risk factors in older age. ${ }^{47}$ An interesting topic for further research would be to investigate whether the dietary habits of the parents are reflected on the eating habits of their children.

\section{CONCLUSIONS}

The parental burden of cardiometabolic disease can be considered as an additional source of influence on children's eating habits and diet quality. Thus, future public health intervention strategies in the family environment should take into consideration, among other factors, the parental burden of disease in their attempt to improve children's eating habits/behavior. However, further investigation is needed to fully understand the exact mechanisms behind the parent-child correspondence recognizing all the potential determinants of children's eating behavior.

\section{Acknowledgments}

The authors would like to thank all the students and parents that took part in the research. Also, they would like to thank all the teachers and school principals who contributed to the sampling process and data collection. Moreover, the authors would like to acknowledge and thank the field investigators of the study: Ilias Kokoris, Athina Fregoglou, Vasiliki Maragou, Marina Mitrogiorgou, Rania Baroucha, Dimitra Kroustalli for their support and assistance with the data collection.

\section{Conflict of interest}

None to declare.

\section{ПЕРІАНЧН}

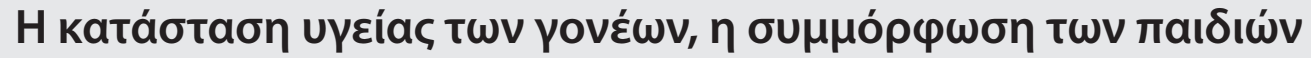

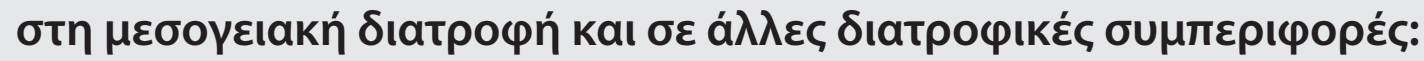

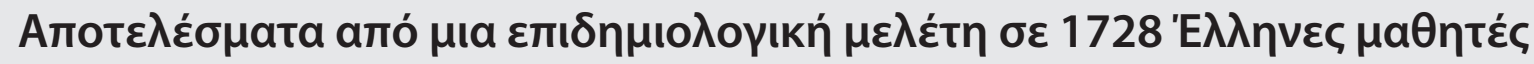

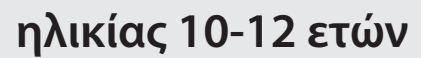

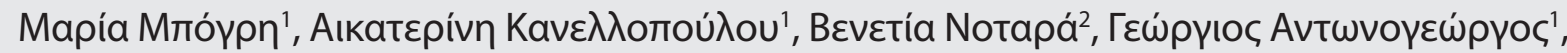

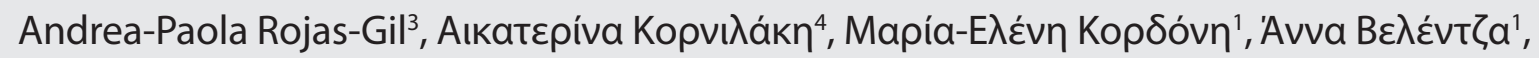

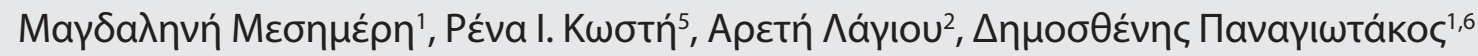

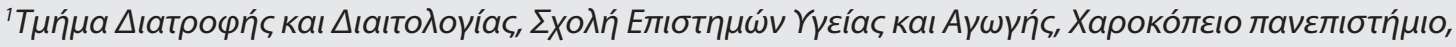

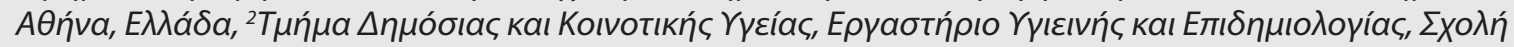

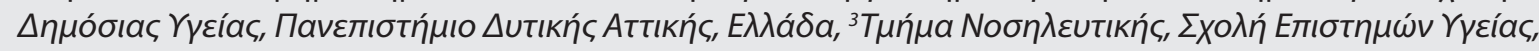

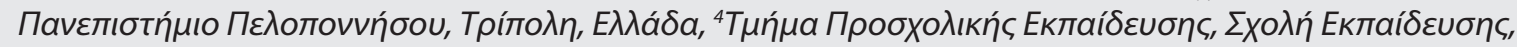

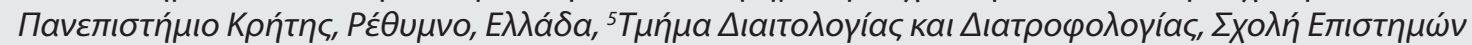

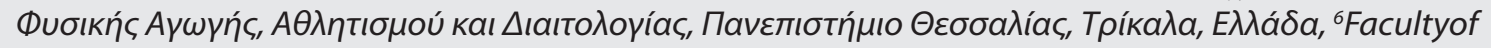
Health, University of Canberra, ACT, Australia

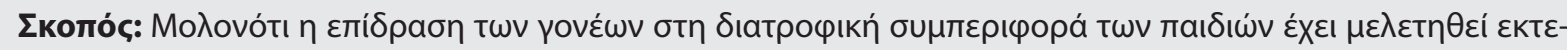

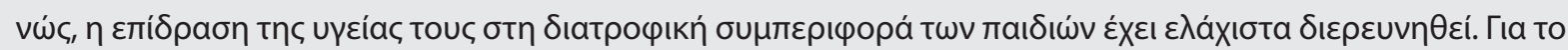




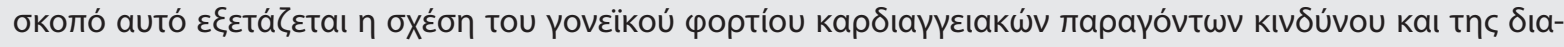

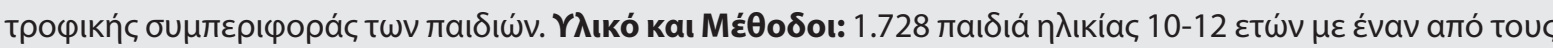

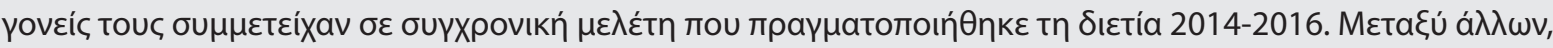

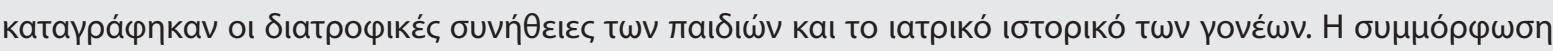

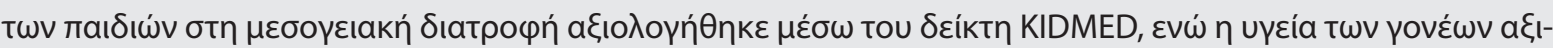

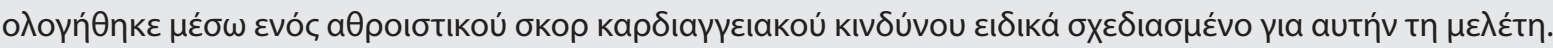

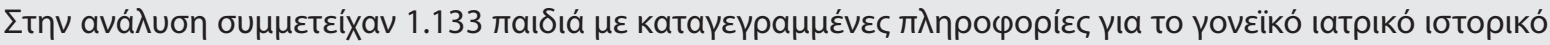

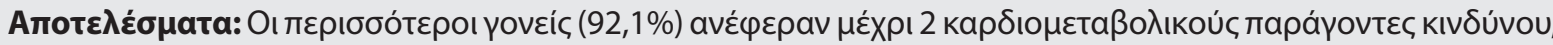

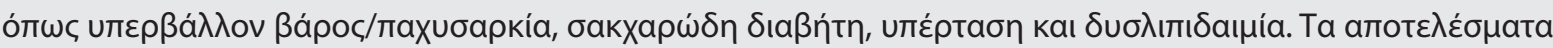

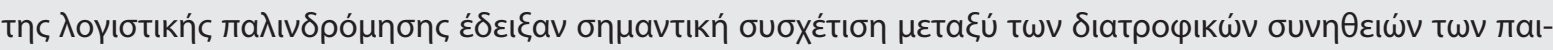

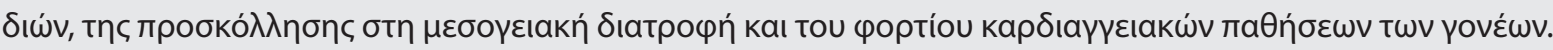

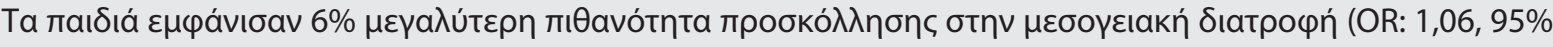

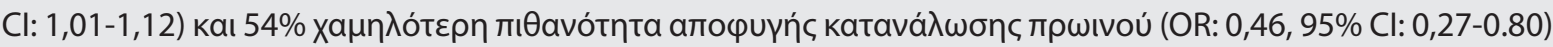

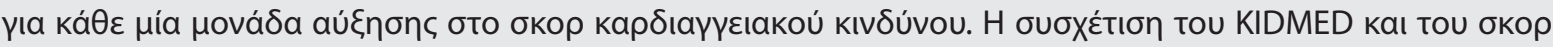

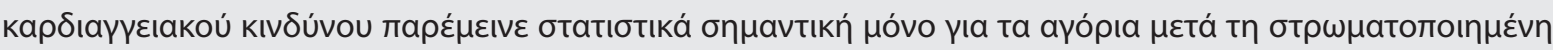

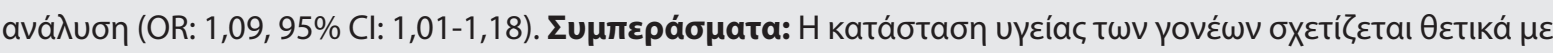

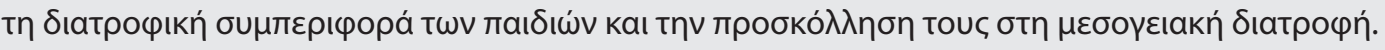

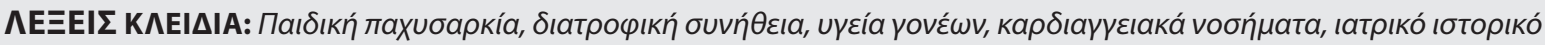

\section{REFERENCES}

1. World Health Organisation. Cardiovascular Diseases 2020 [cited 2020 May 19]. Available from: https://www.who. int/health-topics/cardiovascular-diseases/\#tab=tab_32

2. Piepoli MF, Hoes AW, Agewall S, Albus C, Brotons C, Catapano AL, et al. 2016 European Guidelines on cardiovascular disease prevention in clinical practice: the Sixth Joint Task Force of the European Society of Cardiology and Other Societies on Cardiovascular Disease Prevention in Clinical Practice (constituted by representatives of 10 societies and by invited experts) Developed with the special contribution of the European Association for Cardiovascular Prevention \& Rehabilitation (EACPR). Eur Heart J. 2016 Aug;37(29):2315-81.

3. Kaikkonen JE, Mikkilä V, Raitakari OT. Role of childhood food patterns on adult cardiovascular disease risk. CurrAtheroscler Rep. 2014 Oct; 16(10):443.

4. van de Laar RJ, Stehouwer CD, van Bussel BC, Prins MH, Twisk JW, Ferreira I. Adherence to a Mediterranean dietary pattern in early life is associated with lower arterial stiffness in adulthood: the Amsterdam Growth and Health Longitudinal Study. J Intern Med. 2013 Jan;273(1):79-93.

5. Mikkila V, Rasanen L, Raitakari OT, Pietinen P, Viikari J. Consistent dietary patterns identified from childhood to adulthood: the cardiovascular risk in Young Finns Study. Br J Nutr. 2005 Jun;93(6):923-31.

6. NCD Risk Factor Collaboration (NCD-Risc). Worldwide trends in body-mass index, underweight, overweight, and obesity from 1975 to 2016: a pooled analysis of 2416 population-based measurement studies in 128.9 million children, adolescents, and adults. Lancet. 2017 Dec;390(10113):2627-42.
7. Kumar S, Kelly AS. Review of childhood obesity: from epidemiology, etiology, and comorbidities to clinical assessment and treatment. Mayo Clinic proc. 2017 Feb; 92(2):251-65.

8. Kelder SH, Perry CL, Klepp KI, Lytle LL. Longitudinal tracking of adolescent smoking, physical activity, and food choice behaviors. Am J Public Health. 1994 Jul;84(7):1121-6.

9. Larsen JK, Hermans RC, Sleddens EF, Engels RC, Fisher JO, Kremers SP. How parental dietary behavior and food parenting practices affect children's dietary behavior. Interacting sources of influence? Appetite. 2015 Jun;89:246-57.

10. Cruwys T, Bevelander KE, Hermans RC. Social modeling of eating: a review of when and why social influence affects food intake and choice. Appetite. 2015 Mar;86:3-18.

11. Herman CP, Polivy J. Normative influences on food intake. Physiol Behav. 2005 Dec;86(5):762-72.

12. Shutts K, Kinzler KD, DeJesus JM. Understanding infants' and children's social learning about foods: previous research and new prospects. Dev Psychol. 2013 Mar; 49(3):419-25.

13. Vaughn AE, Ward DS, Fisher JO, Faith MS, Hughes SO, Kremers SP, et al. Fundamental constructs in food parenting practices: a content map to guide future research. Nutr Rev. 2016 Feb;74(2):98-117.

14. McGowan L, Croker H, Wardle J, Cooke LJ. Environmental and individual determinants of core and non-core food and drink intake in preschool-aged children in the United Kingdom. Eur J Clin Nutr. 2012 Mar;66(3):322-8.

15. Fisk CM, Crozier SR, Inskip HM, Godfrey KM, Cooper C, Robinson SM, et al. Influences on the quality of young children's diets: the importance of maternal food choices. Br J Nutr. 2011 Jan;105(2):287-96.

16. Scaglioni S, De Cosmi V, Ciappolino V, Parazzini F, Bram- 
billa P, Agostoni C. Factors Influencing Children's Eating Behaviours. Nutrients. 2018 May;10(6):706.

17. Thomas J, Chan L, Wray A, Miller J, Mehta K, Yaxley A, et al. Does the presence of cardiovascular disease risk factors or established disease influence the dietary intake of affected adults and their children residing in the same household? A secondary analysis of the Australian Health Survey (2011-2013). BMC Cardiovasc Disord. 2017 Jun; 17(1):146.

18. Antonogeorgos GD, Papadimitriou A, Priftis K, Anthracopoulos M, Nikolaidou P, Panagiotakos DB. Validation of a semi-quantitative Food Frequency Questionnaire designed for children aged $10-12$ years: The PANACEAFFQ. Hellenic Journal of Atherosclerosis 2011;1.

19. Serra-Majem L, Ribas L, Ngo J, Ortega RM, Garcia A, PerezRodrigo C, et al. Food, youth and the Mediterranean diet in Spain. Development of KIDMED, Mediterranean Diet Quality Index in children and adolescents. Public Health Nutr. 2004 Oct;7(7):931-5.

20. Mahmood SS, Levy D, Vasan RS, Wang TJ. The Framingham Heart Study and the epidemiology of cardiovascular disease: a historical perspective. Lancet. 2014 Mar; 383(9921):999-1008.

21. Torres-Luque G, Hernandez-Garcia R, Ortega-Toro E, Nikolaidis PT. The Effect of Place of Residence on Physical Fitness and Adherence to Mediterranean Diet in 3(-)5-Year-Old Girls and Boys: Urban vs. Rural. Nutrients. 2018 Dec;10(12):1855.

22. Manios Y, Kourlaba G, Kondaki K, Grammatikaki E, Birbilis $M$, Oikonomou $E$, et al. Diet quality of preschoolers in Greece based on the Healthy Eating Index: the GENESIS study. J Am Diet Assoc. 2009 Apr;109(4):616-23.

23. Panagiotakos DB, Georgousopoulou EN, Pitsavos C, Chrysohoou C, Metaxa V, Georgiopoulos GA, et al. Tenyear (2002-2012) cardiovascular disease incidence and all-cause mortality, in urban Greek population: the ATTICA Study. Int J Cardiol. 2015 Feb;180:178-84.

24. Kontogianni MD, Farmaki AE, Vidra N, Sofrona S, Magkanari F, Yannakoulia M. Associations between lifestyle patterns and body mass index in a sample of Greek children and adolescents. J Am Diet Assoc. 2010 Feb;110(2):215-21.

25. Farajian P, Risvas G, Karasouli K, Pounis GD, Kastorini CM, Panagiotakos DB, et al. Very high childhood obesity prevalence and low adherence rates to the Mediterranean diet in Greek children: the GRECO study. Atherosclerosis. 2011 Aug;217(2):525-30.

26. Gibney MJ, Barr SI, Bellisle F, Drewnowski A, Fagt S, Hopkins $S$, et al. Towards an Evidence-Based Recommendation for a Balanced Breakfast-A Proposal from the International Breakfast Research Initiative. Nutrients. 2018 Oct;10(10):1540.

27. Littlecott HJ, Moore GF, Moore L, Lyons RA, Murphy S. Association between breakfast consumption and educational outcomes in 9-11-year-old children. Public Health Nutr. 2016 Jun;19(9):1575-82.

28. Rong S, Snetselaar LG, Xu G, Sun Y, Liu B, Wallace RB, et al. Association of Skipping Breakfast With Cardiovascular and All-Cause Mortality. J Am Coll Cardiol. 2019 Apr; 73(16):2025-32.

29. Piotrowicz K, Palkowska E, Bartnikowska E, Krzesinski P, Stanczyk A, Biecek P, et al. Self-reported health-related behaviors and dietary habits in patients with metabolic syndrome. Cardiol J. 2015;22(4):413-20

30. Shim JS, Heo JE, Kim HC. Factors associated with dietary adherence to the guidelines for prevention and treatment of hypertension among Korean adults with and without hypertension. Clin Hypertens. 2020 Mar;26:5.

31. Vitale M, Masulli M, Cocozza S, Anichini R, Babini AC, Boemi $M$, et al. Sex differences in food choices, adherence to dietary recommendations and plasma lipid profile in type 2 diabetes - The TOSCA.IT study. Nutr Metab CardiovasC Dis. 2016 Oct;26(10):879-85.

32. Yee AZ, Lwin MO, Ho SS. The influence of parental practices on child promotive and preventive food consumption behaviors: a systematic review and meta-analysis. Int J Behav Nutr Phys Act. 2017 Apr;14(1):47.

33. Patrick $H$, Nicklas TA. A review of family and social determinants of children's eating patterns and diet quality. $J$ Am Coll Nutr. 2005 Apr;24(2):83-92.

34. Nsiah-Kumi PA, Ariza AJ, Mikhail LM, Feinglass J, Binns HJ, Pediatric Practice Research G. Family history and parents' beliefs about consequences of childhood overweight and their influence on children's health behaviors. Acad Pediatr. 2009 Jan-Feb;9(1):53-9.

35. Gillman MW, Rifas-Shiman SL, Frazier AL, Rockett HR, Camargo Jr CA, Field AE, et al. Family dinner and diet quality among older children and adolescents. Arch Fam Med. 2000 Mar;9(3):235-40.

36. Neumark-Sztainer D, Hannan PJ, Story M, Croll J, Perry C. Family meal patterns: associations with sociodemographic characteristics and improved dietary intake among adolescents. J Am Diet Assoc. 2003 Mar;103(3):317-22.

37. Dallacker M, Hertwig R, Mata J. The frequency of family meals and nutritional health in children: a meta-analysis. Obes Rev. 2018 May;19(5):638-53.

38. Kann L, Grunbaum J, McKenna ML, Wechsler H, Galuska DA. Competitive foods and beverages available for purchase in secondary schools--selected sites, United States, 2004. J Sch Health. 2005 Dec;75(10):370-4.

39. UNESCO. Mediterranean diet 2010 [cited 2020 June 1]. Available from: https://ich.unesco.org/en/RL/mediterranean-diet-00884.

40. Estruch R, Ros E, Salas-Salvado J, Covas MI, Corella D, Aros F, et al. Primary Prevention of Cardiovascular Disease with a Mediterranean Diet Supplemented with Extra-Virgin Olive Oil or Nuts. N Eng J Med. 2018 Jun;378(25):e34.

41. Bendall CL, Mayr HL, Opie RS, Bes-Rastrollo M, Itsiopoulos C, Thomas CJ. Central obesity and the Mediterranean diet: A systematic review of intervention trials. Crit Rev Food Sci Nutr. 2018;58(18):3070-84.

42. Buckland G, Bach A, Serra-Majem L. Obesity and the Mediterranean diet: a systematic review of observational and intervention studies. Obes Rev. 2008 Nov;9(6):582-93.

43. Arnett DK, Blumenthal RS, Albert MA, Buroker AB, Goldberger ZD, Hahn EJ, et al. 2019 ACC/AHA Guideline on the primary prevention of cardiovascular disease: executive summary: a report of the American College of Cardiology/ American Heart Association Task Force on Clinical Practice Guidelines. J Am Coll Cardiol. 2019 Sep; 74(10):1376-414.

44. Cosentino F, Grant PJ, Aboyans V, Bailey CJ, Ceriello A, Delgado V, et al. 2019 ESC Guidelines on diabetes, prediabetes, and cardiovascular diseases developed in collab- 
oration with the EASD. Eur Heart J. 2020 Jan;41 (2):255-323.

45. Pereira-da-Silva L, Rego C, Pietrobelli A. The diet of preschool children in the mediterranean countries of the european union: a systematic review. Int J Environ Res Public Health. 2016 Jun;13(6).

46. Yannakoulia M, Panagiotakos DB, Pitsavos C, Stefanadis
C. Correlates of BMI misreporting among apparently healthy individuals: the ATTICA study. Obesity. 2006 May;14(5):894-901.

47. Winham SJ, de Andrade M, Miller VM. Genetics of cardiovascular disease: importance of sex and ethnicity. Atherosclerosis. 2015 Jul;241(1):219-28. 